\title{
Entrevistas com Profissionais como Atividade de Ensino-Aprendizagem Desejável na Formação do Psicólogo
}

\author{
Waldir Bettoi ${ }^{1} 2$ \\ Lívia MathiasSimão \\ Universidadede São Paulo
}

\begin{abstract}
Resumo
O objetivo deste estudo foi o de refletir sobre possíveis interações de atividades de ensino-aprendizagem, especialmente entrevistas feitas com psicólogos sobre sua profissão, com concepções de alunos sobre sua futura profissão de psicólogo(a). Foram analisados questionários, respondidos pelos alunos no início e no final de seu contato com a disciplina, transcrições de entrevistas com psicólogos realizadas pelos alunos e comentários escritos que eles fizeram sobre as entrevistas. Procurou-se, a partir daí, delinear possíveis contribuições das entrevistas na construção de imagens dos alunos sobre a profissão. A análise do conjunto de informações indica que as entrevistas e a reflexão orientada sobre elas podem contribuir para a construção de uma imagem do psicólogo mais próxima de alguém que realiza ações profissionais significativas, ao mesmo tempo que propiciam aos alunos acesso a informações sobre possibilidades de atuação antes desconhecidas, constituindo-se em atividade relevante em sua formação.
\end{abstract}

Palavraschave: Formação do psicólogo; ensino de Psicologia; profissão; concepções de alunos de Psicologia.

Interviewing Professionals as a Desirable Teaching-Learning Activity for Psychology Students

\begin{abstract}
This investigation led to reflections about the possible interactions of some teaching - learning activities (in particular, the student's activity of interviewing professionals working in different areas of application) with students' conceptions about their future profession as Psychologists. The analysis was based on questionnaires answered by the students at the beginning and at the end of the course, transcriptions of the interviews they made and their written comments on these interviews. An outline of the possible contributions of the interviews to the students' constructing of images about profession is presented. The interviews possibly contributed to the constructing of a conception about a professional, revealed at the end of the course, in which he/ she is seen as someone who leads significant professional actions; they may also bring to the students a varied set of information regarding new possibilities of future professional actions and could be considered a relevant teaching - learning activity for psychologist's academic formation.

Keywords: Psychologist professional training; teaching of Psychology; profession; student's conceptions about Psychology.
\end{abstract}

O objetivo do presente trabalho foi levantar suposições relacionais entre concepções de alunos de psicologia sobre sua futura profissão, por um lado, e atividades de ensinoaprendizagem de uma disciplina introdutória de um curso de Psicologia, por outro. Dentre estas atividades, serão focalizadas aqui especialmente entrevistas ao vivo feitas por alunos com profissionais atuantes no mercado de trabalho, sobre sua atuação e profissão.

Este objetivo se coloca a partir do referencial da epistemologiasemiótioo-construtivistaque, como apontamos em outra ocasião (Simão, Bettoi, Cyrus \& Oliveira, 2000), pressupõe que as teorias são oriundas da atividade co-

\footnotetext{
${ }^{1}$ Endereço para correspondência: Universidade de São Paulo, Instituto de Psicologia, Departamento de Psicologia Experimental, Av. Prof. Mello Moraes, 1721, 05508-900, São Paulo, SP. E-mail: bettoi@usp.br

${ }^{2}$ Este artigo é baseado em parte da Dissertação de Mestrado do primeiro autor, realizada sob orientação da segunda autora, apresentada no Programa de Pós-Graduação em Psicologia Experimental do Instituto de Psicologia da Universidade de São Paulo, São Paulo.
}

construtiva do(a) pesquisador(a) e dos(as) participantes da pesquisa, atividade esta que, de partida, recorta opções e propõe uma maneira de ver a natureza da realidade. Nesta perspectiva, o que se busca na atividade de pesquisa não é a garantia de fidedignidade e precisão no retratar uma realidade externa objetiva, mas novas formas de apreensão, no acontecimento empírico, de aspectos pelos quais a realidade se manifesta. A questão da fidedignidade e precisão dá lugar, portanto, no nível teóricometodológico, à questão da plausibilidade e coerência da co-construção do pesquisador a respeito do significado da realidade empírica que, num movimento dialógico, atua na reconstrução teórica. A meta derepresentatividade populacional dá lugar, neste caso, à de busca das possíveis formas com que a diversidade humana se manifesta na busca, dos sujeitos-atores, de "soluções" para questões que aparecem nos contextos situacionais da pesquisa.

Estudos sobre a profissão e a formação do psicólogo não são recentes entre nós. Desde o trabalho pioneiro de 
Sylvia Leser de Mello, "PsicologiaeProfissão em São Paulo", em 1975, a profissão de psicólogo e o papel que o profissional de Psicologia vem desempenhando junto à sociedade brasileira têm sido estudados, discutidos e criticados a partir de ângulos diferentes, abordando-se seus múltiplos aspectos (Ex.: Bastos, 1990; Botomé, 1987, 1988; Carvalho, 1984b; CFP, 1988,1992,1994; CRP6, 1995; Pasquali, 1988; Sindicato dos Psicólogos no Estado de São Paulo, 1984; Witter, Bastos, Bonfim \& Guedes, 1992).

A formação profissional do psicólogo também tem sido objeto específico de reflexão de vários estudiosos que apresentam variadas perspectivaspara aquestão (Ex.: Bastos \& Ashcar, 1994; Carvalho, 1984a; Crochik, 1985; Duran, 1994; Gomide, 1988; Medeiros, 1989; Mello, 1989; Pardo, 1996; Pereira, 1975). Em uma dessas perspectivas, vários estudos abordam a questão das concepções (ou "imagens", como muitas vezes se denominam) de alunos sobre a profissão (Ex.: Carvalho \& Kavano, 1982; Dobrianskyi, 1988; Gomes \& cols., 1996; Lázaro, Oliveira \& Marques, 1986; Leme, Bussab \& Otta, 1989; Lordelo \& Bastos, 1988; Santos, 1989, 1992a 1992b; Santos \& Oliveira, 1995; Schmidt, 1984; Siqueira, Oliveira, Carvalho \& Yamamoto, 1997; Weber, 1991). As relações que estas imagensmantêm com o currículo deformação profissional, eo efeito delas sobrea atuação do profissional são discutidas por Mello (1975) eCarvalho (1982), enquanto Santos(1992b) sugere que se avalie o efeito dos cursos de formação sobre as imagens da Psicologia e da profissão. Weber, Rickli e Liviski (1994) concluem que há uma influência indireta da formação sobre a imagem da Psicologia.

A partir desses estudos, foi suposto que a presença de determinadas atividades de ensino-aprendizagem, já no período inicial do curso, poderia se constituir em uma oportunidade para que, visando a atuação futura, fosse facilitado o acesso a informações e reflexões que alterassem e/ ou complementassem as imagens sobre a profissão que 0 aluno iniciante traz para a faculdade. A relevância desta preocupação se assenta em um aspecto já destacado por Mello (1975): a auto-imagem profissional do psicólogo "condiciona nossos objetivos e define o âmbito de ação dos psicólogos ..." (p. 76)3.

Nestamesma direcão, discutindo o papel quea formação do aluno poderia exercer em sua atuação profissional futura, Carvalho (1982) sugereo "contato com condições concretas em queos psicólogos estão atuando, principalmenteaquelas

\footnotetext{
${ }^{3}$ Esta afirmação converge com consistentes proposições na área da psicologia da ação, e em especial da ação simbólica, derivadas de estudos teórico-empíricos, cuja discussão, entretanto, demandaria maior espaço (veja-se, por exemplo, Boesch, 1991; Valsiner, 1997; Wertsch, 1998).
}

que de alguma forma fujam às atuações convencionais e representem uma expansão nas modalidades de atuação" (p.17). É neste sentido que se entendeo papel das entrevistas como parte das atividades do curso.

Nessa medida, no presente trabalho, examinam-se e discutem-sepossibilidades abertas pelaatividade deentrevista para a formação de alunos de psicologia, no sentido da canalização de seu desenvolvimento (Valsiner, 1997), feita gradualmente por agentes participantes "propositivos" (no caso, maisimediatamente, entrevistadoseprofessor), levando em consideracão o desenvolvimento atual do outro ator (aluno/a), que, por sua vez, também participa ativamente do processo, alterando interpretativamente as estruturas balizadoras da canalização.

Dado, portanto, que o objetivo do trabalho diz respeito a uma relação, o que será apresentado e sistematizado diz respeito a resultados relacionais obtidos a respeito de relayoues entre concepções dos alunos, evidenciadas por respostas a questionários, sendo mantidas, alteradas e reconstruídas pela atividade de entrar em contato com concepções de profissionais durantea atividadede entrevista. Esses resultados relacionais foram organizados e apresentados antecedidos por sub-títulos que acompanham a mesma categorização resultante da análise das concepções evidenciadas nas respostas aos questionários. Ao final, apresenta-seuma síntese conclusiva, em que se procura sistematizar as implicações das relações entre concepções e atividade de entrevista para a formação do aluno.

\section{Método}

A situação empírica tomada para exame constituía-se num contexto multideterminado deinteracõesno desenrolar da disciplina Psicologia Geral, envolvendo pelo menos três categorias de atores sociais: alunos, professor e psicólogos entrevistados pelos alunos. Para a compreensão da natureza desse contexto, é necessário explicitar suas principais características:

- fundamentalmente, os objetivos da disciplina estabeleciam queosalunos: 1) entrassem em contato direto com profissionais de diversas áreas de atuação; e, 2) refletissem sobre diversos aspectos relacionados à atuação do psicólogo, avaliando-a criticamente, especialmenteno quediz respeito às relações dela com a sociedade.

- na direção desses objetivos, foram planejadas as seguintes atividades dos alunos: a) responder a questionários sobre a profissão esobresuaescolhaprofissional, nos primeiro eúltimo dia deaula da disciplina; b) ter contato direto com, no mínimo, três psicólogos(as) de uma mesma área de atuação, através de entrevistas em grupo (asáreasdeatuação eram: clínicaparticular em consultório, organizacional, educacional, institucional/ comunitária, hospitalar epesquisa); c) apresentar trabalho, por 
escrito, e oralmentepara a classe, sobre observações e reflexões apartir da entrevista, quanto àatuação profissional do psicólogo daquelaárea.

- como preparação paraestas atividades, osalunosparticipavam de seminários, quando recebiam e discutiam informações e tinham acesso a referências bibliográficas básicassobreatividades dospsicólogos (para detalhes, veja-se Bettoi, 1998).

\section{Participantes}

1) Alunos/as do primeiro ano de Psicologia de uma universidade particular de São Paulo, na faixa etária de 18 a 20 anos, pertencentesna maioriaà classe média, matriculados na disciplina Psicologia Geral, ministrada pelo primeiro autor deste trabalho, nos períodos da tarde e da noite.

2) Dezoito psicólogos entrevistados pelos alunos (16 do sexo feminino e2 do sexo masculino), predominantemente formados em universidades particulares (privadas ou confessionais), entre 1969 e 1991, tendo, na sua maior parte, iniciado suas atividades profissionais na área um ano após sua graduação; os locais de atuação dos entrevistados, em seu conjunto, foram bastantediversificados: hospitaispúblicos e privados, empresas, instituições bancárias, fundações, escolas públicas e privadas, etc.

\section{Material}

Questionários: Sessenta enovequestionáriosrespondidos pelos alunos, em aplicações realizadas no início e no final do contato com a disciplina, examinando-se as respostas dadas à seguinte questão: Para voç, o que é um profissional (qualquer um, não necessariamenteapenaso psiólogo)?

Transcrições de entrevistas áudio-gravadas: foram examinadas três entrevistas, escolhidas ao acaso, para cada uma das seis áreas de atuação abrangidas pelo trabalho dos alunos: clínica particular de consultório, educacional, organizacional, institucional, hospitalar epesquisa, perfazendo um total de 18 transcrições. Essas entrevistas, elaboradas pelos alunos com a supervisão do professor, eram baseadas em um roteiro comum, abrangendo os principais aspectos relacionados ao exercício da profissão de psicólogo.

Comentários escritos dos alunos sobre as entrevistas: foram analisados 18 comentários escritos de 25 alunos, referentes às entrevistas acima; os comentários respondiam às seguintes perguntas: 1) 0 queeu ache deter feito esta entrevista? e2) 0 queeu achei do queeu ouvi opsiólogo falando?

\section{Procedimentos de Análise}

O procedimento deanálise, resultados e discussão das respostas dos alunos aos questionários foi relatado em oportunidade anterior (Bettoi \& Simão, 2000), e será aqui exposto apenas nos aspectos necessários para oferecer um pano de fundo, de forma a dar sentido contextual às suposições relacionais entre concepções dos alunos sobre a profissão (no início e no final do período da disciplina, evidenciadas pelas respostas aos questionários) eatividade de entrevista com profissionais da área.

A análise do material dos questionários permitiu identificar, tomando como foco a ação profissional, que as respostas dos alunos evidenciavam diferentes concepções do "ser profissional", que foram organizadas em cinco categorias, segundo sua ênfase: 1) no sujeto daação profissional (Ex.: "profissional é uma pessoa interessada no que faz"); 2) na ação profissional propriamente dita (Ex.: "profissional é alguém que realiza projetos"); 3) no modo da ação profissional (Ex.: "profissional éum indivíduo quetrabalha com garra"); 4) no objetivo da ação profissional (Ex.: "profissional é um indivíduo que trabalha para estar bem consigo mesmo"); e, 5) no benefidário da ação profissional (Ex.: "profissional é uma pessoa que ajuda a sociedade").

Além disso, quando os alunos se referiram ao sujeito da ação profissional (categoria 1), o fizeram enfatizando: 1a. suas qualidades pessoais, especialmente em seusaspectos étios, valorativos emorais (Ex.: "profissional é alguém que honra sua profissão"); 1 b. suas qualidades pessoais, mas agora especialmenteem seus aspectosradionaisedecomptêna técnica (Ex.: "profissional é alguém que entende da área") e 1c. a satisfação pessoal do profissional (Ex.: "éum indivíduo que gosta do que faz").

Analogamente, quanto ao modo da ação profissional (categoria 3), os alunos enfatizaram: 3a. a eficiência da ação profissional (Ex.: "é um indivíduo que trabalha com competência”), ou 3b. os aspectosvalorativos, éticosemoraisda ação profissional (Ex.: "trabalha com dedicação e amor").

O trabalho de análise das transcrições das entrevistas resultou na organização de um conjunto de categorias temáticas (que, por razão de espaço, não serão especificadas aqui), referentes a imagens sobre o profissional, a profissão e a áreas de atuação passíveis de serem inferidas do conteúdo de cada uma das entrevistas. Uma descrição detalhada deste material encontra-se em Bettoi (1998). Essa análise permitiu que fossem inferidos, a partir do conteúdo das respostas dos psicólogos, possíveis canalizadores (Valsiner, 1997) das imagens construídas pelos alunos a respeito do profissional, da profissão e da área de atuação do entrevistado. A natureza inferencial desta análise precisa ser aqui comentada: ao mesmo tempo em que se pressupôs que o pesquisador (professor também, no caso) não poderia pretender identificar seguramente as imagens eventualmenteconstruídas pelos alunosa partir da entrevista, pois elas nunca seriam idênticas, por outro lado, o fato de professor-pesquisador, alunos e psicólogos compartilharem do mesmo contexto acadêmico e cultural justifica a utilização desse procedimento, se pensado na 
perspectiva epistemológica delineada de início. Nessa medida, a análise que se apresentará das transcrições das entrevistas será sempre uma construção do pesquisador sobreaspossibilidadesdeconstrução dosalunos, implicando, assim, que os dados apresentados estarão sempre no âmbito daquilo que é possível (em contraposição ao previsível). No presentetrabalho, taisinferências terão a função de auxiliar na compreensão da diversidade das interações de imagens presentes nas entrevistas que foram examinadas, não se pretendendo, nem acreditando que seja possível, portanto, buscar explicações causais para essas interações.

Os comentários escritos dos alunos sobre as entrevistas foram analisados na mesma direção, isto é, inferindo-se possíveis imagens sobre a área, sobre o profissional e sobre a própria realização da entrevista ali presentes. Em seguida, as imagens inferidas a partir das respostas do psicólogo foram cotejadas com aquelas inferidas a partir dos comentários dos alunos, buscando-se apreender possíveis relações (tanto no sentido convergente como divergente) entre ambas as constelações de imagens construídas.

\section{Resultados e Discussão}

\section{Atributos das Imagens Construídas pelos Alunos Indicadas nas Respostas aos Questionários}

A partir da análise das respostas dos alunos aos questionários, pode-se dizer que, de maneira geral, inicialmente os alunos concebiam o profissional como alguém que, fundamentalmente, se definepor seus atributos pessoais, ficando a ação propriamente dita em segundo plano (o quefaz e para quem o faz); ao final do período da disciplina elescontinuavam definindo o profissional por seus atributos pessoais, mas agora com menos ênfase, ao mesmo tempo em que a ação profissional ganhava predominância, passando inclusive a ser vista como prestação de serviços e aplicação de conhecimento.

Quanto ao sujeito da ação profissional, as respostas aos questionários indicaram que, no início do curso, os alunos concebiam o profissional predominantemente como alguém que tem qualidades pessoaistanto relacionadas ao domínio de habilidades racionais eà competência técnica desenvolvida e sempre aperfeiçoada, quanto relacionadas a valores, à moral eà ética. Isto é, o profissional não somente é uma pessoa, mas uma pessoa concebida como dotada de habilidades racionais e possuidora de qualidades éticas e morais das maiselevadas enobres. Para alguns alunos, ainda, o profissional era concebido primariamente como alguém que está satisfeito e ama o que faz.

Ao final da disciplina, as respostas continuaram indicando concepções do profissional como alguém que tem qualidades pessoais, mas agora enfatizando que tais qualidades se relacionam principalmente à posse de conhecimento específico à profissão, conseguido através de sua formação e especialização.

Assim, do início para o final da disciplina, as respostas ao questionário evidenciaram que a concepção de profissional passa por uma transformação em que aspectos racionais das qualidades pessoais do profissional ganham maior ênfase, ao passo que se atenuam os aspectos morais e valorativos da imagem de profissional. Ao final do ano, os alunos, além desses aspectos morais e éticos, vêem na pessoa do profissional outros atributos, especialmente 0 domínio de um saber para o qual se especializou. Perde força a caracterização do profissional exclusivamentebaseada na idéia de que ele é "alguém que gosta do que faz".

Quanto ao modo da ação profissional, a análise das respostas aos questionários também evidenciou transformacõos na concepção de profissional, passando da ênfase inicial nos aspectos ético-valorativos do fazer profissional, sobre os aspectos de competência e eficiência, para um equilíbrio maior entre os atributos na imagem do profissional ao término do ano.

A partir desses resultados, épossível supor que, no início da disciplina, tendo passado recentemente pelo processo de opção profissional, o aluno possa ter se perguntado se ele próprio possuía determinadas características pessoais associadas à suaimagem de profissional e, o queébastante comum no processo de opção profissional de jovens colegiais, diante da ausência de informações específicas e diversificadas sobre 0 fazer profissional, os atributos pessoais da imagem do profissional tenham se enfatizado. A partir do momento em que começa seu curso, 0 aluno passa a entrar em contato com novas informações e questões, trazidas por pessoas que atuam efetivamente na profissão, inclusive através das entrevistas, e a ser encorajado a refletir sobre elas. Estefato tornou plausível erelevante explorar as possíveis interações das concepções indicadas pelas respostas ao questionário com as imagens sobre o profissional delineadas nas entrevistas analisadas.

\section{Atributos das Imagens Construídas pelos Profissionais Indicadas pela Análise das Entrevistas}

O aspecto mais evidente da análise do conteúdo das entrevistas foi a grande diversidade de imagens, sobre um mesmo tema, em entrevistas com psicólogos de uma mesma área, a que os alunos foram expostos. Esta diversidade seconcretizava especialmente em conteúdos que ora se opunham, ora se complementavam, ora se contradiziam, sendo a unanimidade dificilmenteencontrada.

Em contrapartida, a comparação das análises das entrevistas com psicólogos de diversas áreas de atuação 
revelou imagens com conteúdos semelhantes e complementares em entrevistas com psicólogos de diferentesáreas deatuação. Por exemplo, quanto à formação profissional houve recorrência de alguns conteúdos nas diversas áreas: em todas elas foram encontradas sempre menções à inadequação da formação e à necessidade desta ser complementada. Da mesma forma, recorrentemente se depreendeu das respostas dos entrevistados a especificação de alguns prérequisitos pessoais que os profissionais precisam possuir para que possam ser bem sucedidos na sua atuação como psicólogos. A variedade desses atributos pessoais foi grande - desde ter posturas éticas e reflexivas, até ser sério, maduro, ter dom, bom senso, ser criativo, ser dedicado, humilde, idealista - mas eles sempre foram mencionados, independentemente dos entrevistados das várias áreas terem sido explicitamente solicitados a responderem sobre isso. Também recorrente nas imagens dos psicólogos de diferentes áreas de atuação foi a satisfação pessoal: independentemente do salário e das condições de trabalho terem sido considerados adequados, com freqüência o profissional se dizia satisfeito com o que fazia, apresentando-se como alguém cuja atuação "não se afeta por condições concretas detrabalho porque ele ama o que faz", como comentou um aluno.

\section{As Qualidades Pessoais na Imagem de Profissional}

Como já indicamos, nas respostas aos questionários inicial efinal osalunos enfatizaram aquilo que o psicólogo é como pessoa, ficando em segundo plano outros aspectos como a ação profissional propriamente dita, ou o beneficiário dessa ação. Grosso modo, 0 aluno mantém essa característica de sua concepção de profissional, mesmo após ter feito as entrevistas com os psicólogos, indicando a possibilidade de que essa atividade possa ter contribuído no sentido da manutenção da ênfasenas qualidades pessoais do profissional.

De fato, em todas as entrevistas examinadas, 0 entrevistado, de alguma maneira, ao falar do profissional, ou de si enquanto tal, enfoca implícita ou explicitamente suas características pessoais. Implicitamente quando, por exemplo, o psicólogo (entrevista Hospitalar 1), descreve sua trajetória profissional esemostra como pessoa determinada, que sabia o quequeria desde a graduação, mostrando como foi ocupando cargos de responsabilidade e destaque cada vez maiores. Características pessoais são explicitamente mencionadas, por exemplo, quando o entrevistado, ao elencar prérequisitos que o psicólogo deve ter para sua atuação, se refere preponderantemente a características pessoais, como: atitudes e posturas éticas e reflexivas, seriedade, maturidade emocional, dom, empatia com clientes, honestidade (para o clínico); criatividade, interesse, disponibilidade, determinação pessoal, comprometimento, autoconfiança, bom senso, bem estar e desenvolvimento pessoal obtido por terapia, empenho e dedicação (para 0 educacional); ser moralmenteirrepreensível, ter humildade, idealismo, consciência, força de vontade, altruísmo, engajamento político (para o hospitalar); amor pela atividade, altruísmo e idealismo (para o institucional-comunitário); habilidade de comunicação, ter alguma coisa "a mais" que outros profissionais, esforço (para o organizacional); autoconhecimento e treino (para o pesquisador).

Esses resultados convergem com observações de Vilela (1996) a respeito do "ser psicólogo". Entrevistando supervisores de estágios e estagiários de cursos de formação de psicólogos, a autora encontra respostas que parecem revelar a presença de uma imagem de profissional em que seus atributos pessoais também são evidenciados, como no caso da presente pesquisa. Segundo ela, o modelo de profissional encontrado poderia estar revelando 0 predomínio do valor individualista no contexto social onde a Psicologia se insere. Nessa concepção, a formação, representada pelo estágio e supervisão, seria como que "somente um aprimoramento do que já existe pois ser psicólogo é, predominantemente, uma natureza”. (p. 148). Algumas de suas características pessoais específicas estariam representando essa natureza, essa "vocação" para a atividade profissional.

Examinando os atributos pessoais referidos nas entrevistas, identificamos maior ênfase nos aspectos éticos, valorativos e morais das qualidades pessoais do psicólogo do quenos aspectos racionais. Entretanto, nas respostas dos alunos, do questionário inicial para o final, observamos mudança em sentido diferente: uma distribuição praticamente equivalente entreas menções às qualidades éticas emorais e às qualidades racionais do psicólogo deu lugar à ênfase nos aspectos racionais. Este resultado faz atentar para aspectos à primeira vista menos evidentes das entrevistas como atividade geradora de plurissentidos. Defato, apesar de, nas entrevistas, o número de atributos morais e valorativos explicitamente referidos ter sido bastante maior que os racionais, outrosaspectos da condição profissional estiveram implicitamente presentes: 0 entrevistado fala de si, do que faz e de como o faz, dentro de um contexto de atuação em que estão presentes e são necessários aspectos racionais de suas qualidades pessoais, como seu estudo constante, seu treino específico e sua competência para resolver situaçõesproblema. Assim, o profissional aparece, também e principalmente, como alguém que, além de ter determinados atributos valorativos, domina 0 conhecimento psicológico com seus métodos e técnicas.

A entrevista deve ser compreendida então como geradora de polissemia, ganhando relevância por se 
constituir em oportunidadena qual a interpretação seletiva de significado pelos alunos pode ter colaborado para mudanças em suas concepções, evidenciadas de maneira mais pontual pelos questionários inicial efinal.

Nesta mesma perspectiva, o exame de alguns dos comentários dos alunos às entrevistas evidencia a seleção interpretativa na formação das imagens com ênfase na pessoa do psicólogo, ora contendo descrições sobre sua ação profissional, ora contemplando aspectosquese referem a características pessoais do psicólogo no momento da entrevista. Um comentário (Clínica 1) menciona, por exemplo, a disponibilidade e atenção do psicólogo ao responder perguntas, mas ao mesmo tempo sua insegurança einibição, salientando que, apesar deformado há cinco anos, ainda se considera recém-formado e sem experiências. Outros comentários permitem inferir que a formação das imagens também se assenta na avaliação de ações do psicólogo no momento mesmo da entrevista, tais como "saber responder perguntas", "ser objetivo nas respostas", "ser claro". A entrevistatambém pode ensejar um confronto com expectativas criadas por imagens anteriores, oportunizando mudanças, como no caso do aluno queindica estar decepcionado pelo fato de o psicólogo (Hospitalar 2), ter falado pouco, não ter dado respostas diretas eespecíficas, ter se repetido em várias respostas, etc.

Quanto ao aspecto de satisfação pessoal, os questionários inicial e final indicaram que a imagem do psicólogo inclui ele ser alguém que gosta do faz, havendo, entretanto, diminuição às menções a esse atributo no questionário final. O possível papel das entrevistas na geração do contexto de significado em que esta mudança ocorreu seria o de dar acesso ao aluno a informações que relativizam a "satisfação pessoal", segundo seu "grau" e "natureza", já que la estaria sujeita a uma série de determinantes concretos, inerentes à atuação do psicólogo, muitos deles indesejáveis. A satisfação pessoal nem sempre seria possível ou o seria em graus variados.

Entretanto, o exame das respostas dos entrevistados aponta para o fato dequetodos os profissionaismostraramsequasequeincondicionalmentesatisfeitos com sua atuação, mesmo aqueles que mencionaram várias injunções problemáticas para sua atuação. Para os entrevistados, parece que o mero exercício da Psicologia, não importa em que área ou sob quais condições, traz ao psicólogo a gratificação pessoal almejada. Em mais de uma oportunidade, inclusive, afirma-se que a remuneração não deveria ser importante para o psicólogo (por exemplo, em Educacional e Hospitalar). Estaincondicionalidade generalizada pode, por sua vez, ter atuado justamente no sentido de despertar inquietações nos alunos, como no caso do comentário de um deles (Pesquisa 3), afirmando que "jávirou lugar-comum observar que o profissional adora o quefaz, atuando mesmo sem remuneração satisfatória”. Ou seja, a compreensão da importância da atividadedeentrevista estáintimamenteligada ao fato de ela ser considerada o que pode ser: parte (e não todo) da experiência contextual do aluno. Além disso, cada relato do psicólogo também o é no próprio discurso da entrevista, eéa esta organização hierárquica contextual que o interlocutor reage: o psicólogo diz-se satisfeito com sua atuação, ao mesmo tempo em que propicia a formação de imagens relacionadas a outros aspectos dessa atuação, como inadequação de condições de trabalho e remuneração, e frente a isso o aluno vai construindo uma imagem do psicólogo na qual a satisfação pessoal é mais relativa e ponderada.

\section{Modo e os Objetivos da Ação Profissional}

Do início para o final do curso, as respostas dos alunos aos questionários indicaram um aumento de menções a atributos relacionados à ação profissional, eqüivalendose agora às menções a qualidades pessoais.

O exame das entrevistas, por sua vez, permitiu observar a presença de um conjunto muito variado e multifacetado de informações e de elementos capazes de contribuir para a formação de imagens relacionadas à ação profissional e aos inúmeros aspectos que envolvem a profissão de psicólogo, aos quais os alunos tiveram acesso e sobre os quais puderam fazer sua seleção interpretativa. Essecontato com profissionais atuantes que descrevem o que fazem, como fazem, para quê fazem, e em quais circunstâncias o fazem, pode ter atuado na geração de imagens mais ricas da ação profissional, o que se evidenciou pontualmente na distribuição mais equilibrada verificada no questionário final.

Tomando-se como ilustração o espectro da natureza da Psicologia como área de conhecimento e atuação, desde características gerais eâmbito da área deatuação, atémodelo de atuação profissional e abordagens orientadoras, podese encontrar nas entrevistas concepções de Psicologia que envolvem o estudo do comportamento em relação a determinantes variados, ora enfatizando os determinantes individuais, ora os sócio-econômico-culturais, ora os biológicos. Se considerarmos que, em geral, nas concepções iniciais dos alunos, o comportamento aparece como sendo determinado por um único conjunto de fatores, internos e individuais, a exposição às entrevistas poderia ser bastante benéfica no sentido de ampliar a imagem do aluno sobre o tema.

Analogamente, a descrição contextual dasatividades pelo psicólogo, onde aparecem clientela, instituições e casos específicos, traz possibilidade de ampliação dos elementos interrelacionados para os quais a atenção do aluno se volta na compreensão ativa desse universo. É o caso dos relatos 
da atividade clínica pelos entrevistados que, em contraposição à usual imagem inicial do aluno, que se restringe ao exercício da clínica particular de consultório, remetem a imagens que colocam o modelo clínico como referência para a atuação em outros contextos, como 0 dos hospitaise das instituições de saúde, em geral. Aparecem, nas entrevistas, inclusive concepções divergentes quanto à possibilidade de aplicação do modelo nos contextos mencionados, com os psicólogos ora advogando uma atuação baseada em modelos próprios ao contexto (por exemplo, modelos de atuação hospitalar ou institucional), ora explicitando uma atuação baseada em um modelo clínico adaptado àqueles contextos. Mello (1996a), ao comentar as mudanças havidas na profissão desde a publicação de seus primeiros trabalhos, na década de 1970, refere-se a esta ampliação na concepção do que é psicologia clínica, aproximando-a da questão da saúde, como "uma mudança fantástica, fundamental!” (p. 77). A possibilidade de ampliação das concepções das áreas da psicologia, forçando o estabelecimento de interrelações entre elas, dada pelas entrevistas, representaria portanto algo bastante desejável na formação profissional, como também indicam Weber e colaboradores (1994).

Para as abordagens teóricas queo psicólogo utiliza como referencial para sua atuação, valem asmesmas considerações: abordagens como as psicanalítica, kleiniana ou comportamental são mencionadas como presentes em áreas que não se restringem à clínica. Igualmente, o aluno, em relação a este tema, pode ter que lidar com imagens divergentes sobre o papel atribuído pelos psicólogos às abordagens teóricas, na medida em que, para alguns, as referências teóricas não são utilizadas nem necessárias, para outros elas são utilizadas ecleticamente ou, ainda, dogmaticamente, para outros.

Também quanto à questão das condições de trabalho, 0 examedos relatos dos entrevistados mostrou a possibilidade de os alunos serem expostos a diferentes avaliações, e justificativas para essas avaliações, que o profissional apresenta das suas condições de trabalho. Para alguns, essas condições são adequadas porque, dependendo da instituição em que trabalhe, o psicólogo tem seu trabalho reconhecido e valorizado por todos. Para outros, as condições não são adequadas exatamente pela falta de reconhecimento e de valorização social da profissão. Para outros, ainda, as condições são ruins porque dependem das condições políticas e econômicas do país, deficitárias, em geral, ou das instituições, geralmentecarentes. Com a descrição quefazem de suas condições de trabalho, os entrevistados podem ter contribuído para a formação de imagens de que 0 desenvolvimento da carreira do psicólogo é dispendioso e difícil, principalmente no início, exigindo investimentos a longo prazo. Hánecessidadedeatualização constante, obtida às custas do empenho do psicólogo em buscar cursos e oportunidades de prática, para que ganheexperiência, sempre apontada como essencial para sua carreira. O mesmo se deu quanto ao tema correlato das condições do mercado de trabalho, que foram apontadas em geral como insatisfatórias, havendo, entretanto, casos em que os psicólogos se declararam satisfeitos com sua remuneração. Houve inclusive considerações de que o psicólogo não se importa (ou não deveria se importar) com remuneração, seja porque o altruísmo e a benemerência são inerentes à profissão, seja porque o psicólogo deve atuar voluntariamente para obter experiência que 0 auxilie no exercício de sua profissão. Essa situação remete aos dados obtidos e discutidos pelo Conselho Regional de Psicologia - 6⿳亠丷厂 . Região (1996), relativos aos psicólogos inscritos em São Paulo, em que a atuação do psicólogo na condição de voluntário aparece representando um total de aproximadamente $5 \%$ dos vínculos detrabalho examinados. Psicólogos entrevistados pelo Conselho referem-se a este tipo de vínculo como uma forma de aprimorar sua formação universitária, como forma de "tomar contato com realidades que não chegam ao consultório particular", ou como forma de dar uma contribuição à sociedade. A atenção à esta questão parece importante porque, se por um lado, ela pode representar uma alternativa para 0 profissional complementar sua formação insuficiente e exercer sua cidadania, por outro, cabe a suposição de que as imagens relacionadas poderiam, a longo prazo, contribuir para que ospsicólogos, enquanto categoria profissional, não semobilizassem para exigir melhores condições de trabalho e remuneração, ou não as obtivessem em função de não manterem vínculostrabalhistas formaiscom asinstituições.

A autonomia da ação profissional é outro aspecto das imagens que as entrevistas poderiam ter contribuído para construir. Ela aparece ora como total e desejada, fonte da satisfação profissional do psicólogo, ora como inexistente ou relativa. Uma dessas imagens possíveis pode relacionarse, inclusive, à questão da profissão liberal autônoma, apontada por Mello (1975). Tradicionalmente, nas imagens que o aluno traz para seu curso, não só a psicologia é vista como uma profissão liberal autônoma, mas ela seconcretiza através da atuação do psicólogo no consultório particular. Em uma das entrevistas realizadas, na área Organizacional, o psicólogo aponta para o fato de que as perspectivas de melhora do mercado da área, no futuro, dependem do estabelecimento da chamada "terceirização". Isto, por um lado, poderia representar uma alternativa para a ampliação da imagem da profissão como liberal autônoma, anteriormente apenas restrita ao consultório particular. Por outro lado, entretanto, pode-se pensar que a manutenção 
da imagem da profissão com essas características poderia, de alguma maneira, estar contribuindo para que a abrangência social da profissão no futuro continuasserestrita. A adoção dessemodelo, no consultório particular, no Brasil, tem tradicionalmenteimplicado uma atividade dealto custo, de difícil acesso à população como um todo.

\section{Beneficiário da Ação Profissional}

Como foi apontado deinício, a concepção deprofissional quesubjaz aos objetivos da disciplina aqui focalizada prioriza a relação do psicólogo com a sociedade, especialmente quanto à sua contribuição profissional, queéavaliada, entre outros parâmetros, pela abrangência social de seu trabalho. Por isso, pretendeseque, ao final da disciplina, o aluno inclua na sua concepção de profissional aspectos relacionados aos benefícios e beneficiários de sua ação, bem como à relação do psicólogo com os outros sociais, que se evidenciam, por exemplo, na imagem social do psicólogo.

A análise da concepção de profissional apresentada pelos alunos, ao iniciarem seu curso, mostra quesão poucosaqueles cujas concepções fazem menção à sua abrangência social, mesmo em seu sentido mais básico, queseria a mera menção a outro(s) enquanto "clientela". Neste primeiro momento do curso, o profissional é, em geral, apenas uma pessoa (atributos do sujeito) que tem uma atividade (atributos da ação profissional), desempenhada de uma certa maneira (atributos do modo da ação). Na concepção apresentada ao final do curso, observa-se um aumento considerável de menções ao beneficiário da ação profissional: o profissional passa a ser uma pessoa que tem uma atividadedesempenhada em relação a, ou para, outro(s), de uma certa maneira.

Ao se refletir sobre as possibilidades das entrevistas terem contribuído para essa mudança, é importante não se perder de vista que, paralelamente às atividades de entrevista aqui focalizadas, a disciplina envolvevárias outras atividades, tais como leitura e discussão de textos que enfatizam a questão da abrangência social da profissão, consistentemente com os objetivos da disciplina.

Detoda forma, tomadas nesta constelação deatividades, pode-seressaltar quenas entrevistas o psicólogo, ao descrever suas atividades e falar de seu trabalho, ainda que não esteja explicitamente referindo-se à questão da abrangência social da profissão, via de regra, identifica sua clientela, refere-seàs pessoas para quem realiza seu trabalho, bem como aos resultados que obtém ou pretende obter. Nesse sentido, as entrevistas contribuem para que o futuro psicólogo "se localize, isto é, defina o espaço social em que vai atuar, conheça os contornos sócio-econômicos e culturais da população que vai ser atendida, respeite as diferenças que possam existir, elimine preconceitos" (Mello, 1996b, p. 3).
Além disso, a questão da abrangência social da profissão éexplicitamentemencionada pelos entrevistados, seja como prescrição de comportamento ("o psicólogo deveria estar preocupado com a questão da abrangência social de seu trabalho"), seja pela identificação que fazem dos extratos sociaisatingidos concretamente por seu trabalho. Em relação a isso, observa-se que o aluno é exposto a um conjunto variado de avaliações, possibilitando a formação de diferentes imagens em relação à população atingida: desde afirmações de que todos os extratos sociais são beneficiados a ponderações sobre a abrangência desproporcional aos vários segmentos da população, com privilégio para as camadas mais altas.

Esta exposição do aluno à complexidade da questão da abrangência social da profissão pode ser ilustrada por duas das entrevistas. Nelas os entrevistados enfaticamente defendem a necessidade do psicólogo e da psicologia beneficiarem a população como um todo, especialmente a mais pobre, constituindo-se em um aspecto ético-moral da profissão.

Um dos entrevistados, concomitantemente, atende à população pobreatravés de trabalho comunitário, etrabalha em consultório particular, atendendo pessoas de maior renda. É importante notar que a descrição que faz de seu trabalho com a população pobre enfatiza as dificuldades que enfrenta para isso e a remuneração muito baixa que recebe. Apesar disso, declara-se satisfeito com o que faz, obtendo sua sobrevivência econômica através do trabalho em consultório particular. Este tipo de relato pode colaborar na direção da formação de uma imagem profissional menos dicotômica na resolução deum dilema bastante comum entre os alunos iniciantes: o desejo de vir a "ter seu consultório", revestido de atributos como o do prestígio social, e a crítica quanto ao elitismo dessa opção, especialmenteem realidadessócio-econômicascomo a brasileira. $\mathrm{Ou}$, em outros casos, o dilema do desejo de atuar junto à população de baixa renda, exercendo assim sua cidadania também através da profissão, atendendo a seus valores ético-morais, contraposto às expectativas de sucesso econômico e prestígio social ao exercer a profissão.

Na outra entrevista que serve aqui de ilustração, apesar do entrevistado ter um discurso crítico quanto à pequena abrangência social da profissão, atua em uma instituição particular, atendendo às faixas mais ricas da população, atribuindo este fato a uma questão de "ter sorte na profissão". Este tipo de relato confronta o aluno com um aspecto usual de incongruência que pode suscitar reflexões interessantes não só sobre a profissão de psicólogo, mas, mais importante, sobre a psicologia humana à qual 0 psicólogo não deixa de estar submetido. 


\section{Conclusão}

As análise e discussão feitas até aqui, somadas a observações informais que os autores do presente trabalho têm feito, como professores de disciplinas em que se inclui como atividade dos alunos entrevistar profissionais atuantes em São Paulo erefletir sistematicamentesobretais entrevistas, levaram a algumas considerações apresentadas a seguir, a título deconclusão sintética.

Primeiramente, as possibilidades abertas pela entrevista parecem estar relacionadas, em grande parte, ao momento em que esta atividade se dá na disciplina, demandando um contato anterior com aspectos básicos da Psicologia enquanto campo de saber eprofissão, deforma queo aluno, ao interagir com o profissional, játenha delineado um campo semântico, semprenegociável com o interlocutor, em quea entrevista se dará. Essa sugestão vem de encontro ao que Manzini (1991), referindo-se a Ander-Egg, afirma, quando estabelece 0 conhecimento prévio sobre 0 assunto de que a entrevista tratará como um elemento que influi em seu desenrolar.

A entrevista, situada na constelação das atividades de ensino-aprendizagem da disciplina, pode atuar no processo deformação deimagens relacionadasà profissão no sentido de manter, alterar, ampliar e contextualizar as informações e reflexões propiciadas pelas aulas expositivas, leituras e discussões de textos. Trata-se de diferentes naturezas de atividades, idealmente com funções complementares para a reflexão crítica do aluno, por trazerem informações que correspondem a discursos interanimados por diferentes vozes, no sentido bakhtiniano (Wertsch, 1992). Neste sentido, a função das entrevistas parece ser a de oportunizar a percepção de nuances, variações e incongruências, já que cada profissional fala do que faz e como faz em relação a aspectos contextuais diferentes, envolvendo clientela, instituições, condições de trabalho e mercado, etc, possibilitando a construção de imagens menos rígidas e reducionistas a respeito da profissão.

A função convergenteda entrevista com relação às demais atividades da disciplina ocorre, por exemplo, quando os entrevistados fazem afirmações de tal forma coincidentes com as feitas pelo professor econtidas nos textos discutidos em classe, que se apresentam como "exemplo vivos e concretos" daquilo que o professor e o texto haviam conceituado em sala de aula. Ou então quando a descrição do profissional, por ser de tal modo ligada ao contexto da atividade, resulta em riqueza deinformações que oferecem base significativa para a reflexão sobre a realidade profissional (descrições detalhadas do funcionamento de instituições, por exemplo, vistas pelo profissional como necessárias à compreensão das atividades que desenvolve).

Complementarmente, a entrevista tem função divergente em relação às demais atividades da disciplina quando, por exemplo, revela um profissional que tem características incongruentes ou incompatíveis com as valorizadas por outras "vozes" sobre a profissão, como o discurso do professor ou os textos lidos e discutidos em classe. 0 relevante aqui é que a divergência criada pela entrevista traz, concomitantemente, uma impossibilidade de reducionismo na formação da imagem de profissional, uma vez que ele, profissional, se revela durante a entrevista com "múltiplas características positivas enegativas convivendo" (Ex.: o profissional que se revela ao aluno como "eclético", aspecto bastante criticado em textos lidos e discussões realizadas, mas, ao mesmo tempo claro em suas respostas, disponível, inteligente, gentil, etc.).

Os comentários dos alunos sobre a própria atividade de entrevista (Bettoi, 1998) indicam as múltiplas tentativas de refletir sobre congruências e divergências na imagem da profissão propiciadas pelas várias atividades da disciplina e pelas diversas entrevistas (Ex.: quando um aluno estabelece relações entre o que ouviu na entrevista e o que aprendeu em classe: "como vimos em classe, tanto o curso quanto aimagem da população, influenciam a forma como atua").

Entretanto, é importante que não se perca de vista que, além dos aspectos racionais envolvidosno entrevistar e refletir sobre a entrevista, a formação de imagens, enquanto ação simbólica, envolve igualmente aspectos afetivo-emocionais (Boesch, 1991; Simão, 1999, 2001), donde a importância da qualidade do contato pessoal entre os interlocutores. A simpatia do aluno pelo profissional, as emoções e sentimentos de estar frente a um psicólogo "ao vivo", bem como os sentimentos e motivações deste ao se dispor a ser entrevistado, o lugar ou papel que coloca para si na situação, modularão não só o tom, mas também a natureza do conteúdo temático da entrevista. Os comentários dos alunos sobre as entrevistas são indicativos de emoções experimentadas em relação à entrevista e à pessoa do psicólogo entrevistado. A maior parte deles menciona ter gostado, com diferentes intensidades, de fazer as entrevistas. Em relação ao entrevistado, os comentários também mostram diferentes graus de afetividade presentes. Em pontos extremos, gosta-se ou não do psicólogo entrevistado ou da entrevista. Mas foi possível também não gostar de algumas características de seu entrevistado, mas considerar a entrevista válida em termos informativos. Não se 
coloca, portanto, na perspectiva aqui adotada, a questão da veracidade das informações obtidas, mas sim a questão de que as informações obtidas foram as selecionadas pelos interlocutores como relevantes diante desta ou daquela configuração interativa, criada e negociada ao longo da própria entrevista. Cabe lembrar aqui as implicações do caráter eminentemente interativo da entrevista, tal como discutido por Blanchet (1988, 1989), Manzini (1991), Manzini e Simão (2001), Tunes e Simão (1998), dentre outros, na medida em que o entrevistador coloca tarefas cognitivas a serem resolvidas, que orientam as seleções e inferências do entrevistado; este, por sua vez, é quem detém, por assim dizer, o acesso ao fenômeno que é tema do diálogo. Há, portanto, no processo de entrevista, necessidade das partes regularem-se em função das suas verbalizações, o que permite a inclusão de perguntas não previstas no roteiro, bem como reformulação de perguntas e respostas no curso da interação. Estas características dos processos deinteração verbal representam, de acordo com Manzini (1991), vantagens no uso de entrevistas sobre outras técnicas de acesso a informações, na medida em que permitem tanto a obtenção de "respostas mais precisas do informante", como a possibilidade do entrevistador "captar, através da circunstância de interação que cerca a entrevista (gesto, tom de voz, postura física), as reações do entrevistado às perguntas" (p. 153).

Em síntese, os resultados da pesquisa indicam que a entrevista é oportunidade relevante para a formação profissional, na medida em que o aluno pode, através dela, refletir sobrea profissão ecriticála, com base em referenciais mais próximos da atuação concreta do psicólogo, dentro de sua realidade profissional. Isto nos leva, mais uma vez, na direção das reflexões de Mello (1996b) sobre a formação do psicólogo: "o despertar de questões, o fornecer mais elementos para a reflexão e para a crítica do que para 0 dogmatismo, são instrumentos mais formativos do que uma extensa aprendizagem de técnicas" (p. 3).

De forma mais ampla, acreditamos que a exposição do aluno a situações em que ele experimente o contato com a diferença e a diversidade que caracterizam a Psicologia como área de conhecimento e profissão pode lhe ser educacionalmente valioso, não apenas enquanto futuro profissional, mas também enquanto indivíduo em desenvolvimento. De fato, ainda que informalmente, percebe-se que o aluno, no início de sua formação, tem uma expectativa de que o curso lhe traga uma versão una da Psicologia, e que esta lhe traga verdades seguras e versões únicas dos fatos, coerentemente com sua tendência a examinar as situações segundo alternativas dicotômicas mutuamente excludentes ${ }^{4}$. Assim, por exemplo, ao entrar em contato com a questão daabrangência social da profissão, e assumi-la enquanto valor que deve nortear a atuação do psicólogo, passa a classificar os profissionais em duas categorias únicas: rapidamente, os psicólogos que têm ganho razoável e função social pouco abrangente se tornam os "bandidos" da profissão, enquanto os "mocinhos" serão aqueles abnegados que ganham pouco e dedicam sua vida a trazer benefícios à população pobre. De início, os inúmeros matizes da realidade da profissão e as soluções criativas emergentes dadas pelos profissionais como construtores da história da profissão ainda não se mostram presentes para o aluno. As entrevistas esua análise reflexiva orientada pelo professor e pela discussão com os pares parece, pois, contribuir para alterar a situação apontada por Mello (1996b), de que os cursos de formação do psicólogo não contribuem para que ele se torne capaz de conviver com as divergências, características da Psicologia, que acabam sendo incorporadas dogmática e intransigentemente. A isto também se refere Figueiredo (1992), quando discute o dogmatismo e o ecletismo como atitudes provocadas pela angústia e atordoamento vividos por estudantes e psicólogos, frente à constatação de que 0 conhecimento psicológico se caracteriza pela divergência e não por uma convergência ou unicidade esperadas. 0 desdobramento talvez mais grave, tanto das atitudes dogmáticas quanto das ecléticas, é que elas, como que num "efeito rebote", restringem progressivamente a disponibilidadeindividual para a experiência com a alteridade, num movimento auto-protetor, impedindo que o indivíduo "se faça outro no contato com o outro", como explicita Figueiredo (1992), remetendo a Heidegger (p. 18).

O exame das entrevistas agrupadas por área (Bettoi, 1998) mostrou várias possibilidades de formação de imagens diferentes pelo aluno, que ora se complementam, ora se opõem, em relação aos vários temas abordados. Por exemplo, as avaliações que os profissionais fazem do mercado de trabalho na área, presente e futuro, mostram perspectivas das mais otimistas às mais desanimadoras. Igualmente diversificado é o conjunto de afirmações sobre formação do profissional, considerada às vezes satisfatória, outras vezes bastante inadequada ou carecendo de complementação posterior à graduação. Igualmente, quanto às condições oferecidas para a atuação na área, encontra-se um amplo leque de possibilidades apresentadas aos alunos. As condições de trabalho são excelentes para alguns, são

\footnotetext{
${ }^{4}$ Poder-se-ia especular sobre razões interrelacionadas, que tocam desde às teorias do senso comum, até à valorização da visão positivista da ciência pela escola e pela mídia, o que, entretanto, foge ao âmbito deste artigo.
} 
péssimas, para outros, ou são "relativas", isto é, dependem de alguma coisa. Um outro exemplo é a avaliação feita quanto à autonomia da qual o profissional desfruta na sua atuação, ora considerada total, ora parcial, ora inexistente. Em termos do contato com a diversidade dos tipos humanos que caracterizam os profissionais, pode-se dizer, igualmente, queasentrevistas seconstituem em oportunidade para que a diversidade seja experimentada.

Finalmente, éimportanteque sereflita sobre o inevitável papel canalizador (Valsiner, 1998) do professor, eventualmente privilegiado, no processo de formação das imagens pelos alunos, o que remete a questões sobre a própria concepção do processo de ensino-aprendizagem como culturalmente situado e eticamente comprometido.

Como consideração final, pode-se sugerir que os resultados obtidos na presente investigação reafirmam a necessidade dos cursos de formação profissional serem objeto de estudo dos psicólogos, para que se conheça criticamente o papel que as diversas atividades de ensino podem desempenhar sobre sua atuação profissional futura.

\section{Referências}

Bastos, A. V. B. (1990). Mercado de trabalho: Uma velha questão e novos dados. Psioologia, Ciência e Profissão, 10(2,3,4), 28-39.

Bastos, A. V. B. \& Ashcar, R. (1994). Dinâmica profissional e formação do psicólogo: Uma perspectiva de integração. Em Conselho Federal de Psicologia (Org.), Psicólogo Brasileiro: Práticas emergentes e desafios para a formação (pp. 245-271). São Paulo: Casa do Psicólogo.

Bettoi, W. (1998). Interação de condiọoes de ensino presentes em disciplina de curso de Psicologia com œncepgõese expectativas descusalunos sobrea profisã̃o. Dissertação de Mestrado não-Publicada, Programa de Pós-Graduação em Psicologia, Universidade de São Paulo. São Paulo, SP.

Bettoi, W. \& Simão, L. M. (2000). Profissionais para si ou para outros? Algumas reflexões sobre a formação dos psicólogos. Psicologia, Ciência e Profissão, 20(2), 20-31.

Blanchet, A. (1988). Complémentations et interprétations d'un interviewer dans l'entretien de recherche. Psychologie Française, 33(4), 280-288.

Blanchet, A. (1989). Les relances de l'interviewer dans l'entretien de recherche: Leurs effets sur la modalisation et la déictisation du discours de l'interviewé. L' Anné Psychologique, 89, 367-391.

Boesch, E. E. (1991). Symbolic action theory and cultural psychology. Berlin, Heidelberg: Springer- Verlag.

Botomé, S. P. (1987). Mercado de trabalho e campo profissional em Psicologia: Limitações, possibilidades e perspectivas [Resumos]. Em Sociedade de Psicologia de Ribeirão Preto (Org.), Resumos de comunicaōões científicas, XVII Reunião Anual de Psiologia da SPRP (p. 341). Ribeirão Preto: SPRP.

Botomé, S. P. (1988). Em busca de perspectivas para a Psicologia como área de atuação e como campo profissional. Em Conselho Federal de Psicologia (Org.), Quem é o psiólogo brasileiro? (pp. 273-297). São Paulo: Edicon/Educ.

Carvalho, A. M. A. \& Kavano, E. A. (1982). Justificativas de opção por área de trabalho em Psicologia: Uma análise da imagem da profissão em psicólogos recém-formados. Psioologia, 8, 1-18.

Carvalho, A. M. A. (1982). A profissão em perspectiva. Psiølogia, 8, 5-17.

Carvalho, A. M. A. (1984a). Atuação psicológica: Alguns elementos para uma reflexão sobre os rumos da profissão e da formação. Psiologia, Ciência e Profissão, 2, 7-9.
Carvalho, A. M. A. (1984b). Modalidades alternativas de trabalho para psicólogos recém-formados. Cadernos de Análise do Comportamento, 6, 114.

Conselho Federal de Psicologia (1988). Quem é o psioólogo brasileiro? São Paulo: Edicon/Educ.

Conselho Federal de Psicologia (1992). Psiólogo brasileiro: Construção de novos espagos. Campinas: Átomo.

Conselho Federal de Psicologia (1994). Psiólogo brasileiro: Práticas emergentes e desafios para a formação. São Paulo: Casa do Psicólogo.

Conselho Regional de Psicologia - 6믈 Região (1995). Psioologia: Formação, atuação profissional e mercado de trabalho. São Paulo: CRP-06.

Conselho Regional de Psicologia - 6a . Região (1996). Psicólogo busca aprimoramento em trabalho voluntário. Jornal do CRP, 98(mar/abr), 14.

Crochik, J. L. (1985). Uma proposta de análise da formação do psioólogo em nossa røalidade. Dissertação de Mestrado não-Publicada, Programa de PósGraduação em Psicologia, Universidade de São Paulo. São Paulo, SP.

Dobrianskyi, L. N. (1988). Percepção das áreas de atuação e expectativas em relação à futura ação profissional [Resumos] . Em Sociedade de Psicologia de Ribeirão Preto (Org.), Resumos de comunicaũoes científicas, XVIII Reunião Anual de Psiologia da SPRP (p. 99). Ribeirão Preto: SPRP.

Duran, A. P. (1994). Alguns dilemas na formação do psicólogo: Buscando sugestões para superá-los. Em Conselho Federal de Psicologia (Org.), Psicólogo brasileiro: Práticas emergentes e desafios para a profissão (pp. 273-310). São Paulo: Casa do Psicólogo.

Figueiredo, L. C. M. (1992). Convergências e divergências: A questão das correntes de pensamento em psicologia. Transin-formação, 4(1,2,3), 1526.

Gomes, W. B., Teixeira, M. A. P., Crescente, D. B., Fachel, J., Sehn, L. \& Klarmann, P. (1996). Atitudes e crenças de estudantes universitários sobre psicoterapia e psicólogos. Psicologia: Teoria e Pesquisa, 12(2), 121127.

Gomide, P. I. C. (1988). A formação acadêmica: Onde residem suas deficiências. Em Conselho Federal de Psicologia (Org), Quem é 0 psiólogo brasileiro? (pp. 69-85). São Paulo: Edicon/Educ.

Lázaro, C. S., Oliveira, F. A. L. \& Marques, T. M. (1986). Motivos de escolha do curso de Psicologia: Comparação da percepção inicial e ao término do curso [Resumo]. Em Sociedade de Psicologia de Ribeirão Preto (Org.), Resumos de comunicaõoses científicas, XVI Reunião Anual de Psiologia da SPRP (p. 135). Ribeirão Preto: SPRP.

Leme, M. A. V. S., Bussab, V. S. R. \& Otta, E. (1989). A representação social da Psicologia e do Psicólogo. Psicologia, Ciência e Profissão, 9(1), 29-35.

Lordelo, E. R. \& Bastos, A. V. (1988). Representação social do psicólogo [Resumos]. Em Sociedade de Psicologia de Ribeirão Preto (O rg.), Resumos de œmunicaọ̃es científics, XVIII Reunião Anual de Psiologia da SPRP (p.12). Ribeirão Preto: SPRP.

Manzini, E. J. (1991). A entrevista na pesquisa social. Didática, 26/27, 149158.

Manzini, E. J. \& Simão, L. M. (2001). Formas de raciocínio apresentadas por deficientes mentais: Um estudo por meio de interações verbais. Em E. J. Manzini (Org.), Linguagem, œgnição eensino do aluno œm deficiência (pp. 57-87). Marília, SP: UNESP - Marília.

Medeiros, J. G. (1989). O currículo como objeto de pesquisa. Psiologia, Ciência e Profissão, 9(1), 24-25.

Mello, S. L. (1975). Psiologia e profissão em São Paulo. São Paulo: Ática.

Mello, S. L. (1989). Currículo: Quais mudanças ocorreram desde 1962? Psioologia, Ciência e Profissão, 9(1), 16-18.

Mello, S. L. (1996a). Entrevista com Sylvia Leser de Mello. Estudos de Psiologia, 1(1), 76-89.

Mello, S. L. (1996b). Formação, informação e disposição ética. Jornal do Federal, 42,3.

Pardo, M. B. L. (1996). Contribuições de um modelo de análise para 0 estudo do fenômeno formação profissional do psicólogo. Em E. Bonfim (Org.), Formaọões em Psioologia: Pós-graduação e graduação (pp. 7893). Belo Horizonte: ANPEPP/UFMG. 
Pasquali, L. (1988). Condições de trabalho do psicólogo. Em Conselho Federal de Psicologia (Org.), Quem é o psiólogo brasileiro? (pp. 149-162). São Paulo: Edicon/Educ.

Pereira, S. L. M. (1975). A formação profissional dos psicólogos: Apontamentos para um estudo. Psiologia, 1(1), 15-20.

Santos, G. T. \& Oliveira, D. S. (1995). Concepções acerca da relação PsicologiaCiência, apresentadas por estudantes de Psicologia [Resumos]. Em Sociedade de Psicologia de Ribeirão Preto (Org.), Resumos de cmunicaọoes científicas, XXII Reunião Anual de Psiologia da SPRP (p. 220). Ribeirão Preto: SPRP.

Santos, M. A. (1989). Psicólogo: Atuação profissional e função social, segundo a percepção de estudantes de Psicologia. Estudos de Psiologia, 1, 5-30.

Santos, M. A. (1992a). “O que é Psicologia?’: Representação social da profissão entre alunos do curso de formação [Resumos]. Em Sociedade de Psicologia de Ribeirão Preto (Org.), Resumos de cmunicaōões científicas, XXII Reunião Anual de Psicologia da SPRP (p. 125). Ribeirão Preto: SBP.

Santos, M. A. (1992b). Áreas de atuação em Psicologia: A (des)construção da imagem social da profissão e da identidade profissional do psicólogo [Resumo]. Em Sociedade de Psicologia de Ribeirão Preto (Org.), Resumos de œmunicaōoes científicas, XXII Reunião Anual de Psiølogia da SPRP (p. 134). Ribeirão Preto: SPRP.

Schmidt, M. L. S. (1984). Psiologia: Representaōoes da profissão. Dissertação de Mestrado não-Publicada, Programa de Pós-Graduação em Psicologia, Universidade de São Paulo. São Paulo, SP.

Simão, L. M. (1999). Ação, interação, objeto e cultura: A contribuição de Ernst Boesch. [CD-ROM]. Em Conselho Regional de Psicologia (3a. Região)/ Departamento de Psicologia da UFBA (Org.), Resumos de comunicayoues científicas, I Congresso N orteN ordeste de Psiologia. Salvador: Conselho Regional de Psicologia (3 ${ }^{\text {a }}$. Região)/Departamento de Psicologia da UFBA.

Simão, L. M. (2001). Boesch's symbolic action theory in interaction. Culture \& Psychology, 7(4), 485 - 493.

Simão, L. M., Bettoi, W., Cyrus, D. H. T. \& Oliveira, M. S. (2000). A pesquisa de processos de construção de conhecimento durante interações sociais: algumas questões teórico metodológicas. [CD-ROM]. Em Conselho Regional de Psicologia (3a. Região)/Departamento de Psicologia da UFBA (Org.), Resumos de comunicaọoes científicas, II Congresso NorteNordeste de Psioologia. Salvador: Conselho Regional de Psicologia (3a. Região)/Departamento de Psicologia da UFBA.
Sindicato dos Psicólogos no Estado de São Paulo (1984). 0 perfil do psiólogo no Estado de São Paulo. São Paulo: Cortez.

Siqueira, G. S., Oliveira, S. C. C., Carvalho, D. B. \& Yamamoto, O. H. (1997). Psicologia e escolha profissional: A imagem da profissão no RN [Resumos]. Em Sociedade Brasileira de Psicologia (Org.), Resumos de cmunicagões científicas, XXVII Reunião Anual de Psiologia da SBP (p. 130). Ribeirão Preto: SBP.

Tunes, E. \& Simão, L. M. (1998). Sobre análise do relato verbal. Psioologia USP, 9(1), $303-324$.

Valsiner, J. (1997). Culture and the development of dhildren's action: A theory of human development. New York: John Wiley.

Valsiner, J. (1998). The guided mind: A sociogenetic approach to personality. Cambridge, MA: Harvard University Press.

Vilela, A. M. J. (1996). Formar-se psió́logo: Como ser "livre œmo um pássaro". Tese de Doutorado não-Publicada, Programa de Pós-Graduação em Psicologia, Universidade de São Paulo. São Paulo, SP.

Weber, L. N. D. (1991). A representação social do psicólogo em Curitiba. Psiologia Argumento, 9, 71-90.

Weber, L. N. D., Rickli, A. \& Liviski, J. D. (1994). Atuação e formação do psicólogo como fatores que influenciam a representação social da Psicologia. Psicologia Argumento, XV, 71-88.

Wertsch, J. V. (1992). Voiøs of the mind. Cambridge, MA: Harvard University Press.

Wertsch, J. V. (1998). Mind as action. New York - Oxford: Oxford University Press.

Witter, G. P. , Bastos, A. V. B., Bonfim, E. M. \& Guedes, M. C. (1992). Atuação do psicólogo: Espaços e movimentos. Em Conselho Federal de Psicologia (Org.), Psioólogo brasileiro: Construção de novos espaços (pp. 161-177). Campinas: Átomo.

\section{Sobre os autores}

Waldir Bettoi éPsicólogo, MestreeD outorando em Psicologia pela Universidadede São Paulo. Docentede Psicologia.

Lívia Mathias Simão éPsicóloga, Doutora em Psicologia pela Universidadede São Paulo. Docente do Instituto de Psicologia da Universidade de São Paulo.

Recebido: $13 / 11 / 2001$

1a Revisão: 22/01/2002

Última Revisão: 18/06/2002

Aœite Final: 20/06/2002 